\title{
Elbow Dislocation with Ipsilateral Galeazzi Fracture: A Case Report
}

\author{
Anani Abalo*, Koulima K. Akloa, Yaovi Yannick Dellanh \\ Department of Orthopaedics, Tokoin Teaching Hospital, Lomé, Togo \\ Email: *abalgreg@yahoo.fr
}

How to cite this paper: Abalo, A., Akloa, K.K. and Dellanh, Y.Y. (2016) Elbow Dislocation with Ipsilateral Galeazzi Fracture: A Case Report. Open Journal of Orthopedics, 6, 276-282.

http://dx.doi.org/10.4236/ojo.2016.69036

Received: August 11, 2016

Accepted: September 17, 2016

Published: September 20, 2016

Copyright $\odot 2016$ by authors and Scientific Research Publishing Inc. This work is licensed under the Creative Commons Attribution International License (CC BY 4.0).

http://creativecommons.org/licenses/by/4.0/

\begin{abstract}
Elbow dislocation associated with ipsilateral Galeazzi fracture is a rare pattern of injury. Only seven cases were reported in the literature. We reported another case in a 42 years old man. Closed reduction of the dislocated elbow joint was immediately performed under sedation. Because the patient did not want surgery for radius, it was decided to manage the fracture conservatively. The lack of clinical improvement motivated operative treatment for Galeazzi fracture 56 days after injury. We have discussed the treatment option and the result obtained. The prognosis of this associated injury is related to the DRUJ dislocation, which should not be misdiagnosed.
\end{abstract}

\section{Keywords}

Dislocation, Elbow, Distal Radio-Ulnar Joint, Galeazzi Fracture, Radius

\section{Introduction}

The elbow dislocations can be isolated or associated with fractures around the elbow [1]-[3]. Radius fracture associated with radio-ulnar joint dislocation is known as Galeazzi fracture [4] [5]. The combination of elbow dislocation and Galeazzi fracture is a rare pattern of injury. Only seven cases have been reported in the literature [6]-[12]. The mechanism causing both elbow dislocation and fracture of Galeazzi has been reported [6] [8]. Their management and good result have been reported [9] [10] [12].

We reported another Galeazzi fracture associated with posterolateral dislocation of the elbow. The particularity of this case was his neglected aspect. The treatment of the Galeazzi fracture was made 56 days post traumatic. We have discussed the therapeutic possibilities as well as the functional outcome of the forearm.

\section{Observation}

We have received in consultation a 42 years old male, for a mobility deficit of left elbow 
and wrist. He was right-handed, with no known medical history. After road traffic accident (falling from a bike), He has been admitted in a district hospital (level 2 hospital) on $29 / 03 / 2013$. The clinical and radiological assessment has concluded a posterolateral elbow dislocation associated with fracture of the left radius with no other lesions or neurovascular (Figure 1). Closed reduction of the dislocated elbow joint was immediately performed under sedation. Because the patient did not want surgery for radius, it was decided to manage the fracture conservatively. The lack of clinical improvement motivated this consultation in our hospital on the 20/05/2013.

In our examination, we have noted a stiffness of the left elbow $\left(0 / 30^{\circ} / 95^{\circ}\right)$, a limitation of the prono-supination with a forearm fixed in pronation $35^{\circ}$, stiffness in wrist extension and a posterior protrusion of the ulnar head. The distal radio-ulnar joint (DRUJ) stress test and piano key sign were positive. A new X-ray reported the reduction of the elbow, radius malunion and DRUJ dislocation (Figure 2a and Figure 2b).

We then concluded that, after the road traffic accident, our patient has had a posterolateral elbow dislocation associated with Galeazzi fracture. After explanations, he accepted the surgery. Neither wrist arthrogram nor MRI was done. The patient underwent open reduction internal fixation of the radial shaft malunion fracture using locking compression plate through a standard volar approach of Henry. After internal fixation the DRUJ was found to be unstable. The DRUJ instability was treated with ligament reconstruction as described by Fulkerson and Watson [13]. The wrist was immobilized by a splint for 3 weeks, followed by rehabilitations. The patient was reviewed monthly.

At 13 months follow-up, the patient has regained full flexion and extension of elbow and wrist a supination deficit with full pronation $\left(75^{\circ} / 0 / 90^{\circ}\right)$ and consolidation of the fracture (Figure 3 ). He has no pain. He reported being very satisfied with the result, returned to his previous occupation.

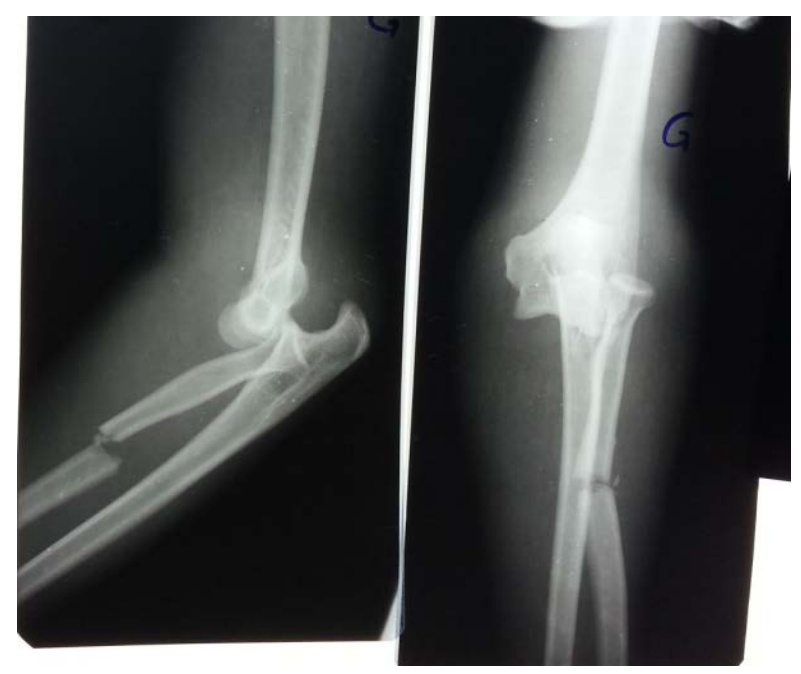

Figure 1. Anteroposterior and lateral radiographs demonstrating elbow dislocation and radius shaft fracture. The wrist was not seen. 


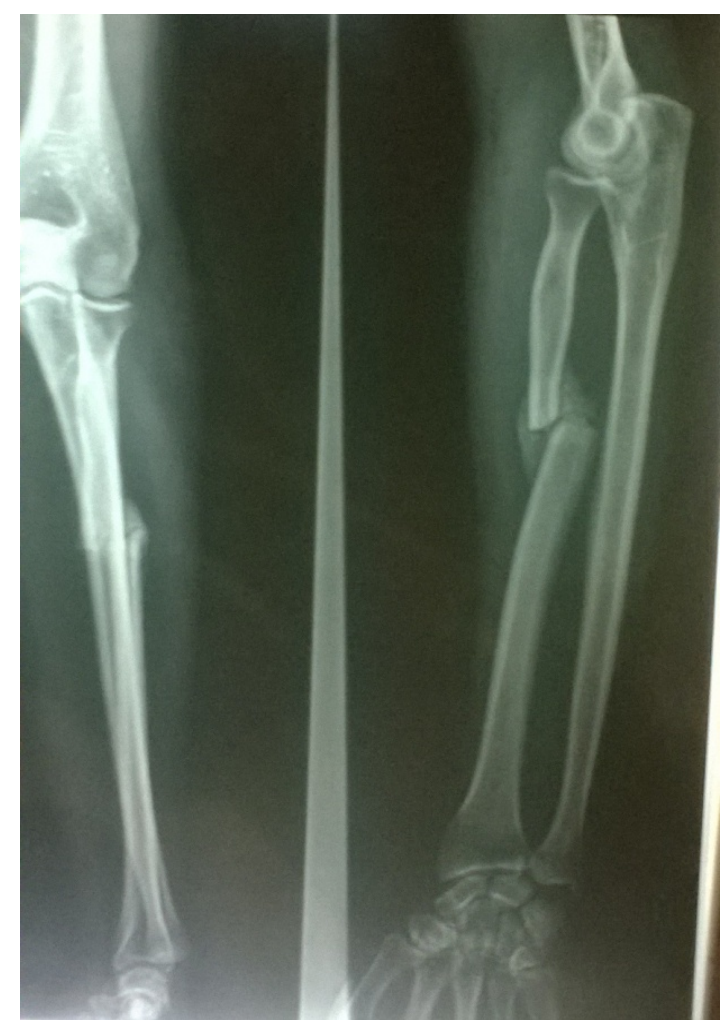

(a)

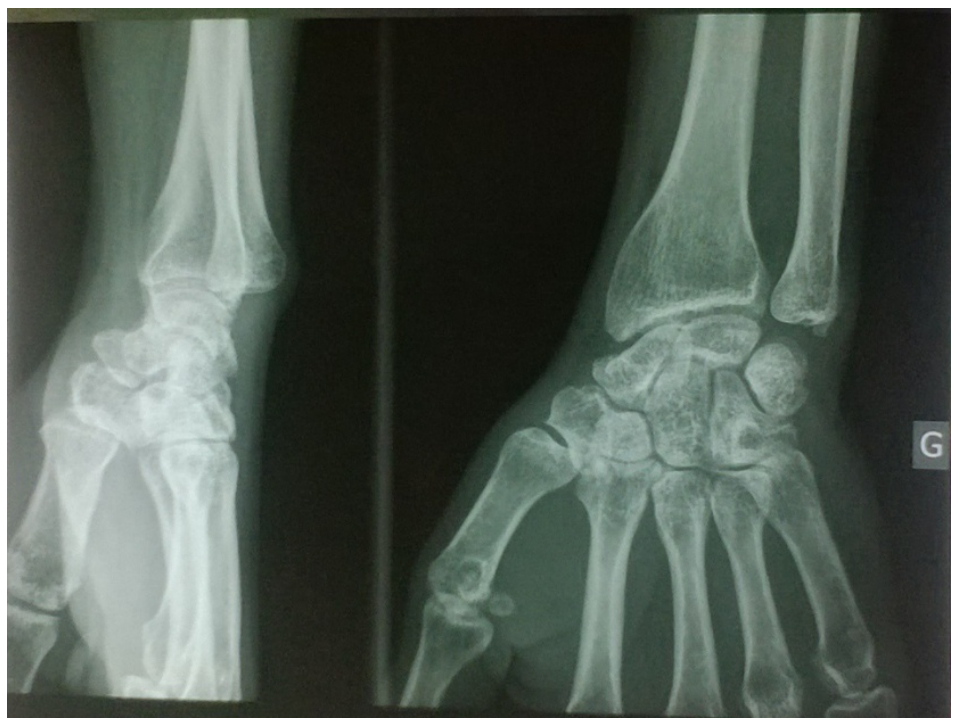

(b)

Figure 2. (a) and (b): radiographs did in our hospital at 8 weeks showing the radius malunion and the DRUJ dislocation.

\section{Discussion}

Dislocations of the elbow can be associated with fractures. The most common are dislocations of the elbow and fractures of the radial head and coronoid [2] [14]; dislocations 


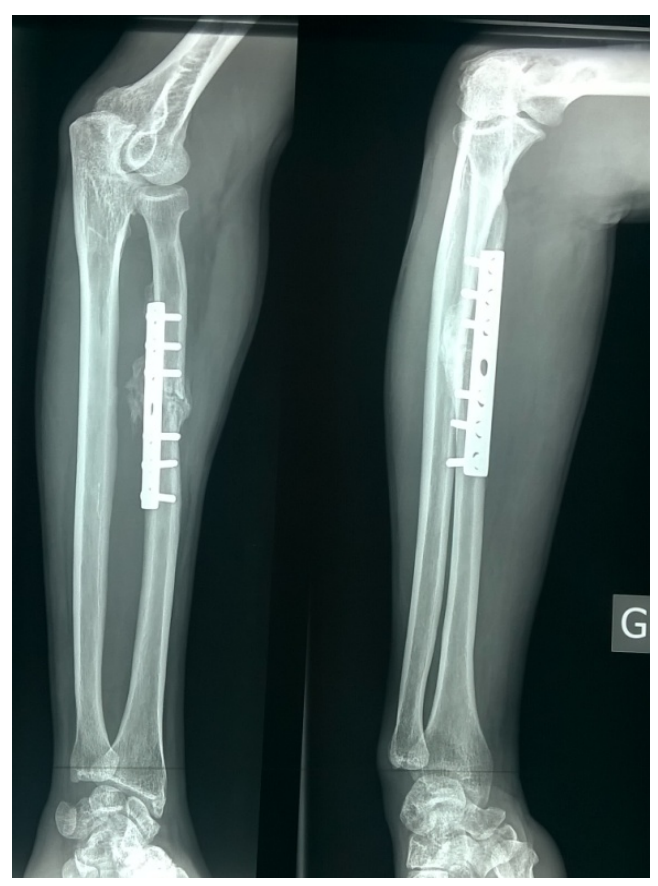

Figure 3. Follow-up X-ray 13 months post operatively showing united radial shaft fracture and enlocated elbow and DRUJ.

of the elbow and diaphyseal fractures of one or the two bone of the forearm [3] [15].

But the entity elbow dislocation and ipsilateral Galeazzi fracture of is not very well documented. It can be confusing with elbow dislocation associated with an isolated fracture of the radius. In the published literature, only seven cases of this entity have been reported (Table 1).

This lesion was often seen after falling from a height or road traffic accident [5] [9]. The high energy of the trauma would have generated the Galeazzi fracture and the elbow dislocation [9]-[11].

The diagnosis in all reported cases was done urgently. Except Rajeev et al. [7] who have reported a case in whom the elbow lesion was found five weeks later after the treatment of the Galeazzi fracture. For not thinking about these associated injuries, the first doctor who has consulted our patient has mixed the diagnosis. We thought that in our daily practice, we have to often think of this lesion entity by focusing on clinical and radiographic examination on the wrist. But our experience has shown that pain, plaster-cast immobilization, or associated deformity, often does not allow a true lateral radiograph to be made.

All authors agree for surgical treatment of the radius fracture [6] [11]. The treatment of DRUJ dislocation was orthopedic except in three patients who received a pinning of the distal radio-ulnar joint [6] [8] [9]. For the elbow dislocation, only two patients underwent a surgical procedure: one to repair the medial collateral ligament [7] and one for fixation of coronoid process in addition to repair ligament [9]. All these authors reported good results. 
Table 1. Literature review of ipsilateral Galeazzi fracture and elbow dislocation.

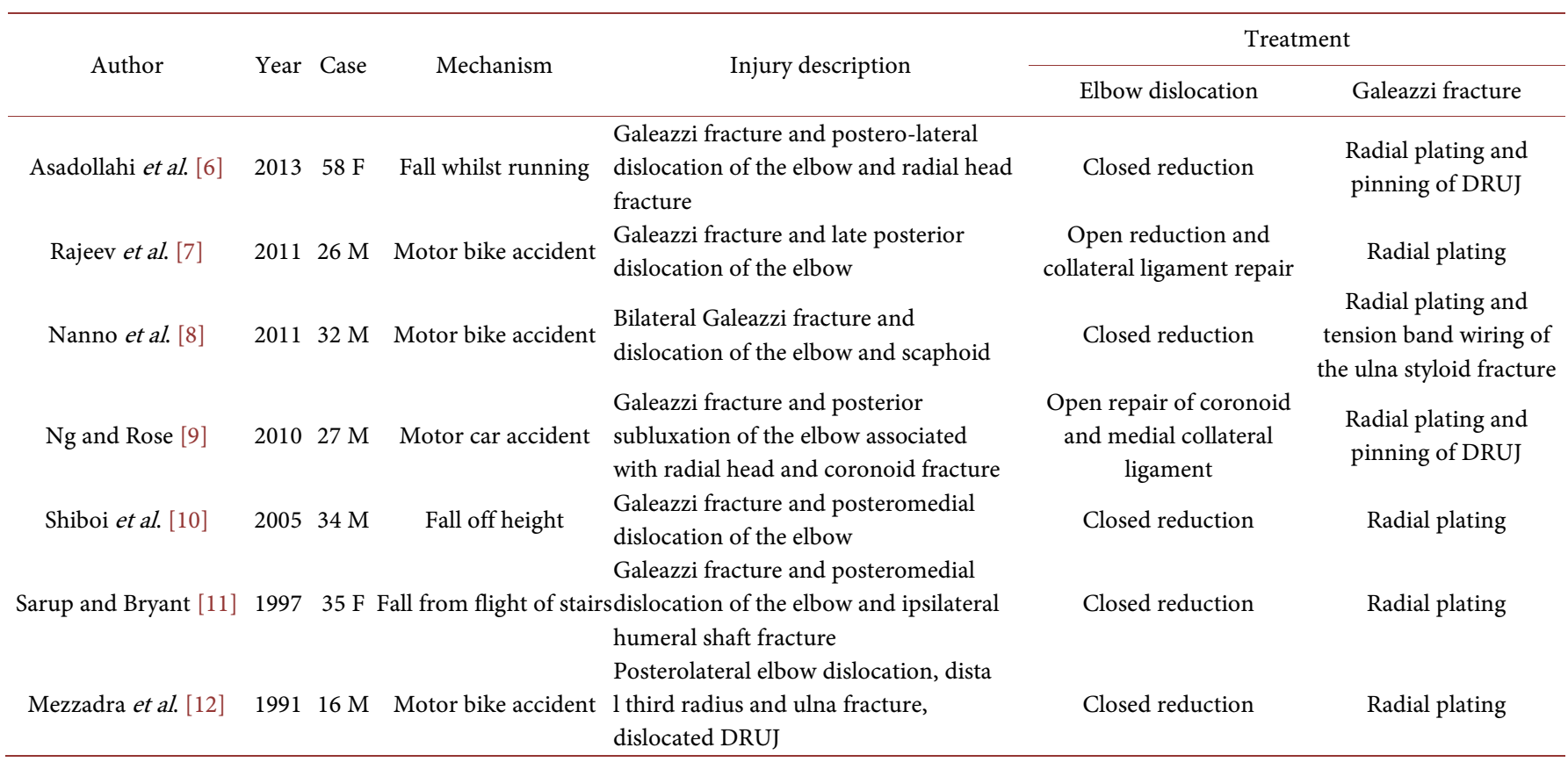

Thus, seen early and treated early, the result obtained is good [16]. But for neglected cases, we think the prognosis is related to the DRUJ injury. So for our patient, the challenge has been the management of DRUJ injury. After fixation of the radial fracture, we have long hesitated before approaching the distal radio-ulnar joint, because of lack of exploration before surgery. The pathogenesis of DRUJ instability is complex and poorly understood. Numerous ligament reconstruction methods have been described for the treatment of DRUJ instability [17] [18]. Soft tissue procedures can be classified into 3 groups: extraarticular direct radioulnar tethering, methods that provide indirect radioulnar stability with tenodesis or an ulnocarpal sling, and methods involving radioulnar ligament reconstruction [17] [19]. Ulnocarpal tenodesis does not provide sufficient stability.

Ligament reconstruction can be performed extra or intra-articularly. Extra-articular repairs aim to establish stability between the radius and ulna [17] [18]. Intraarticular procedures in general are technically demanding, and affect secondary stabilizers [17] [20]. Also, most anatomical reconstruction techniques require drilling a hole for the passage of a graft in the foveal part of the ulna, which is the exit point of vessels that feed the TFCC. We therefore gave preference to an extraarticular technique which we think is easier than intra-articular techniques. But some limitation of supination and pronation is a possible sequela [18]. Our patient has a little limitation of the supination. But till now, as he was very satisfied with the result, we said wait and see.

\section{Conclusion}

The elbow dislocation associated with ipsilateral fracture of Galeazzi is a rare pattern injury. Radius fracture should be treated surgically. Elbow dislocations and the DRUJ 
can be managed non-operatively, with a satisfactory functional outcome. The prognosis of this associated injury is related to the DRUJ dislocation, which should not be misdiagnosed.

\section{References}

[1] Hobgood, E.R., Khan, S.O. and Field, L.D. (2008) Acute Dislocations of the Adult Elbow. Hand Clinics, 24, 1-7. http://dx.doi.org/10.1016/j.hcl.2007.11.012

[2] Pierrart, J., Bégué, T., Mansat, P. and GEEC (2015) Terrible Triad of the Elbow: Treatment Protocol and Outcome in a Series of Eighteen Cases. Injury, 46, S8-S12. http://dx.doi.org/10.1016/S0020-1383(15)70004-5

[3] Goni, V., Behera, P., Meena, U.K., Gopinathan, N.R., Akkina, N. and Arjun, R.H. (2015) Elbow Dislocation with Ipsilateral Diaphyseal Forearm Bone Fracture: A Rare Injury Report with Literature Review. Chinese Journal of Traumatology, 18, 11311-11315. http://dx.doi.org/10.1016/j.cjtee.2014.10.004

[4] Atesok, K.I., Jupiter, J.B. and Weiss, A.P. (2011) Galeazzi Fracture. Journal of the American Academy of Orthopaedic Surgeons, 19, 623-633. http://dx.doi.org/10.5435/00124635-201110000-00006

[5] Eberl, R., Singer, G., Schalamon, J., Petnehazy, T. and Hoellwarth, M.E. (2008) Galeazzi Lesions in Children and Adolescents: Treatment and Outcome. Clinical Orthopaedics and Related Research, 466, 1705-1709. http://dx.doi.org/10.1007/s11999-008-0268-6

[6] Asadollahi, S., Shepherd, D. and Hau, R.C. (2013) Elbow Fracture-Dislocation Combined with Galeazzi Fracture in Adult: A Case Report and Literature Review. International Journal of Surgery Case Reports, 4, 748-752. http://dx.doi.org/10.1016/j.ijscr.2013.04.032

[7] Rajeev, A., Senevirathna, S. and Harrison, J. (2011) Subacute Dislocation of the Elbow Following Galeazzi Fracture-Dislocation of the Radius: A Case Report. Journal of Medical Case Reports, 5, 589. http://dx.doi.org/10.1186/1752-1947-5-589

[8] Nanno, M., Sawaizumi, T. and Takai, S. (2011) Case of Bilateral Galeazzi Fractures Associated with Dislocation of the Right Elbow. Journal of Nippon Medical School, 78, 384-387. http://dx.doi.org/10.1272/jnms.78.384

[9] Ng, V.Y. and Rose, S. (2010) Combined Elbow Fracture-Dislocation and Galeazzi Fracture in an Adult: A Case Report and Review of the Literature. Current Orthopaedic Practice, 21, 330-333. http://dx.doi.org/10.1097/BCO.0b013e3181d4b9e4

[10] Shiboi, R., Kobayashi, M., Watanabe, Y. and Matsushita, T. (2005) Elbow Dislocation Combined with Ipsilateral Galeazzi Fracture. Journal of Orthopaedic Science, 10, 540-542. http://dx.doi.org/10.1007/s00776-005-0938-0

[11] Sarup, S. and Bryant, P.A. (1997) Ipsilateral Humeral Shaft and Galeazzi Fractures with a Posterolateral Dislocation of the Elbow: A Variant of the "Floating Dislocated Elbow". Journal of Trauma, 43, 349-352. http://dx.doi.org/10.1097/00005373-199708000-00024

[12] Mezzadra, A., Gusmeroli, E., Tettamanzi, M., Prestianni, B. and Molinari, D. (1991) A Rare Injury to the Upper Limb: Elbow Dislocation Combined with Galeazzi Fracture-Dislocation. Italian Journal of Orthopaedics and Traumatology, 17, 567-572.

[13] Fulkerson, J.P. and Watson, H.K. (1978) Congenital Anterior Subluxation of the Distal Ulna. A Case Report. Clinical Orthopaedics and Related Research, No. 131, 179-182.

[14] Zha, G., Niu, X., Yu, W. and Xiao, L. (2015) Severe Injury of Bilateral Elbow Joints with Unilateral Terrible Triad of the Elbow and Unilateral Suspected Terrible Triad of the Elbow Complicated with Olecranon Fracture: One Case Report. Int J Clin Exp Med, 8, 14214- 
14220.

[15] Hung, S.C., Huang, C.K., Chiang, C.C., Chen, T.H., Chen, W.M. and Lo, W.H. (2003) Monteggia Type 1 Equivalent Lesion: Diaphyseal Ulna and Radius Fractures with a Posterior Elbow Dislocation in an Adult. Archives of Orthopaedic and Trauma Surgery, 123, 311-313. http://dx.doi.org/10.1007/s00402-003-0526-8

[16] Park, M.J., Pappas, N., Steinberg, D.R. and Bozentka, D.J. (2012) Immobilization in Supination versus Neutral Following Surgical Treatment of Galeazzi Fracture-Dislocations in Adults: Case Series. Journal of Hand Surgery (American Volume), 37, 528-531. http://dx.doi.org/10.1016/j.jhsa.2011.12.021

[17] Adams, B. (2000) Anatomic Reconstruction of the Distal Radioulnar Ligaments for DRUJ Instability. Techniques in Hand \& Upper Extremity Surgery, 4, 54-60. http://dx.doi.org/10.1097/00130911-200009000-00003

[18] Scheker, L.R. and Ozer, K. (2004) Ligamentous Stabilization of the Distal Radioulnar Joint. Techniques in Hand \& Upper Extremity Surgery, 8, 239-246. http://dx.doi.org/10.1097/00130911-200412000-00007

[19] Mittal, R., Kulkarni, R., Subsposh, S.Y. and Giannoudis, P.V. (2004) Isolated Volar Dislocation of Distal Radioulnar Joint: How Easy to Miss! European Journal of Emergency Medicine, 11, 113-116. http://dx.doi.org/10.1097/00063110-200404000-00012

[20] Bain, G.I., Pourgiezis, N. and Roth, J.H. (2007) Surgical Approaches to the Distal Radioulnar Joint. Techniques in Hand \& Upper Extremity Surgery, 11, 51-56. http://dx.doi.org/10.1097/bth.0b013e318033bdae

\section{Submit or recommend next manuscript to SCIRP and we will provide best service for you:}

Accepting pre-submission inquiries through Email, Facebook, LinkedIn, Twitter, etc. A wide selection of journals (inclusive of 9 subjects, more than 200 journals)

Providing 24-hour high-quality service

User-friendly online submission system

Fair and swift peer-review system

Efficient typesetting and proofreading procedure

Display of the result of downloads and visits, as well as the number of cited articles

Maximum dissemination of your research work

Submit your manuscript at: http://papersubmission.scirp.org/

Or contact ojo@scirp.org 